TECHNICAL TRANSACTIONS 1/2019

ENVIRONMENTAL ENGINEERING

DOI: $10.4467 / 2353737$ XCT.19.010.10050

\author{
Bernard Twaróg (iD orcid.org/0000-0003-3150-1409 \\ btwarog@pk.edu.pl \\ Faculty of Environmental Engineering, Cracow University of Technology
}

\title{
THE ANALYSIS OF THE REACTIVE WORK OF THE ALDEN TURBINE
}

ANALIZA PRACY REAKCYJNEJ TURBINY ALDENA

\begin{abstract}
In the analysis of the reactive work of the Alden turbine, two systems of energy recovery were utilized: conical, a straight suction pipe, and a curved diffusor - the so-called bend. The simulations executed on both the systems allowed the operation and selected installation components to be described. Full distribution curves for pressures, velocities were presented, and spectral analyses of pressure fluctuations for the selected points over and under the turbine rotor were also performed. For some structural parts, by means of the FSI - Fluid System Interaction model - the distributions of main stresses and strains according to von Mises theory were illustrated. Additionally, the shapes of deformed installations parts caused by unsymmetrical loads generated mainly by a turbulent water flow were presented.

Keywords: hydropower, Alden turbine, hydrodynamic cavitation, hydrodynamic loads, vortex core, suction pipe
\end{abstract}

\section{Streszczenie}

W prezentowanej analizie pracy reakcyjnej turbiny Aldena wykorzystano dwa systemy odzyskiwania energii: rurę ssącą w postaci stożkowej oraz krzywaka. Symulacje wykonane w obu systemach pozwolity na prezentacje wyników oraz szczególowy opis pracy wybranych komponentów instalacji. Przedstawiono krzywe zmian ciśnień oraz prędkości, a także przeprowadzono analizę spektralną pulsacji ciśnienia dla wybranych punktów nad i pod wirnikiem turbiny. W przypadku wybranych elementów konstrukcyjnych z zastosowaniem teorii FSI zilustrowano rozkłady naprężeń według teorii von Misesa. Ponadto przedstawiono ksztalty zdeformowanych części instalacji spowodowane przez niesymetryczne obciążenia generowane glównie przez turbulentny przeplyw wody.

Słowa kluczowe: turbina Aldena, hydrodynamiczna kawitacja, siły hydrodynamiczne, rdzeń wiru, rura ssąca 


\section{Introduction}

The idea of an eco-friendly Alden turbine (Fig. 1) was born in 1993 [1]. Two main assumptions, viz. an improvement in efficiency and a reduction of environmental impact determined the trends for developing a new turbine structure. A concentration of work resulted in a radically new construction for the turbine rotor. The number of blades was limited, both pressure and velocity gradients were reduced, the clearance between the rotor and the guide vane was minimalized, and eventually, the size of flow spaces was maximized.

a)

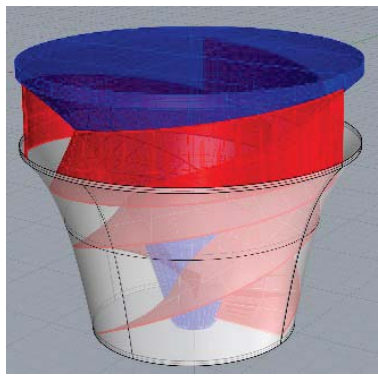

Fig. 1. Alden turbine rotor used in the modelling: a) model, b) template [1]

The selection of Alden turbines takes place according to 2 parameters: head and flow [3]. In particular, a hydraulic head for the Alden turbine is assumed ranging from 7.6 to $43[\mathrm{~m}]$ and a minimum flow rate from $14\left[\mathrm{~m}^{3} / \mathrm{s}\right]$ onwards [3]. Typical parameters are the values of the head, rotational speeds and power. Rational diameter values for the Alden turbine range from 2.4 to $4.5[\mathrm{~m}]$ [3]. For diameters under $2.4[\mathrm{~m}$ ], the spacing of turbine parts (vanes and spaces among them) will diminish unfavourably, which reduces the fish survival rate. Instead, large diameters will mean inefficiency in the system. An appropriate rotational speed of the Alden turbine amounts to $90-140$ [rpm] [3].

\section{Principals of CFD modelling}

The model for the installation under analysis was developed in the Flow-3D software. the viscous and turbulent flow was assumed, without taking into consideration the limited compressibility of water. The spinning parts have been described by means of the General Moving Objects, made available in the Flow-3D interface. For the description of water, a time-averaged form of the Navier-Stokes (N-S) equations, known also as the Reynolds equation, was applied:

$$
\rho\left(\frac{\partial \bar{U}_{l}}{\partial t}+\bar{U}_{J} \frac{\partial \bar{U}_{l}}{\partial x_{j}}\right)=\frac{\partial}{\partial x_{j}}\left(\sigma_{i j}\right)+\bar{F}_{l}
$$

where $U, p, \rho, F$ stand, respectively, for velocity, pressure, fluid density and body force. 
The expression $\left(\sigma_{T}\right)_{i j}$ which does not appear in the N-S equations, represents the Reynolds stress tensor:

$$
\begin{gathered}
\sigma_{i j}=-\bar{p} \delta_{i j}+v \rho\left(\frac{\partial \bar{U}_{l}}{\partial x_{j}}+\bar{U}_{J} \frac{\partial \bar{U}_{J}}{\partial x_{i}}\right)-\left(\sigma_{T}\right) i j \\
\left(\sigma_{T}\right)_{i j}=\rho \overline{u_{l} u_{J}}
\end{gathered}
$$

An extra term, viz. $\left(\sigma_{T}\right)_{i j}$ is a symmetric Reynolds stress tensor whose elements constitute components of unitary, turbulent momentum flux.

For an extra term which appears in N-S equations, this will entail a closing hypothesis. It is the domain of turbulence models. Historically, the first hypothesis was a proposal for closing the system of N-S equations formulated by Prandtl (1925), nowadays referred to as the concept of 'mixing length model'. Yet, the most numerous group is composed of models based upon the Boussinesq model, which assumes the occurrence of the so-called eddy viscosity which corresponds to the coefficient of fluid molecular viscosity. Prandtl's hypothesis belongs to the first group of 'viscous' models, commonly referred to as the class of zero-equation models which do not need extra differential equations in order to close the N-S system of equations. Another group of viscous models for closing the N-S equations utilizes the equation of transport of turbulence kinetic energy (TKE) " $\kappa$ ". The first model of this class was also proposed by Prandtl (1945). These models represent the class of one-equation models which, due to the introduction of the TKE equation, will concern the specific nature of the process of energy transmission in a cascade of turbulent vortexes. A veritable breakthrough in this branch was, however, the publication of the proposal of Harlow and Nakayama (1968) nowadays known as the model Standard " $\kappa-\varepsilon$ ". In this concept, the system of (N-S) equations was closed with two additional differential equations of transport, but to the " $\kappa$ " equation of transport, already known, one added the equation of dissipation rate of turbulence kinetic energy (TKE) " $\varepsilon$ ", and this value could be assessed by means of the Kolmogorov hypothesis:

$$
\varepsilon=\frac{k^{3 / 2}}{l}
$$

in which the macroscopic flow length (expressed by the linear scale of flow "l") is linked to dissipation, which describes the smallest eddy scales. Soon after, other two-equation models were developed, of which most popular became the hypotheses " $\kappa-\kappa l$ " and " $\kappa-\omega$ " of Rodi and Spalding (1970).

The applied turbulence model $R N G \kappa-\varepsilon$ [4] constitutes an expansion of the model Standard $\kappa-\varepsilon$. It satisfies the assumptions of physics of turbulent flows and selected mathematical assumptions for Reynolds stresses, which eventually will increase the efficiency of this model. The model is suitable for complex flows with fast variations of fluid parameters, moderate turbulences and local disturbances. It can guarantee high efficiency in the case of both flows around a body and straight flows, taking into consideration the boundary layer, 
rotations, stream detaching and recirculation. The constants in $\kappa-\varepsilon$ equations are obtained by means of the theory of renormalization groups. This model is more efficient than the model Standard $\kappa-\varepsilon$ in the case of complex flows with densely arranged stream lines, vortexes and cases where the stream is detached.

a)

$H W \div+27.40 m$

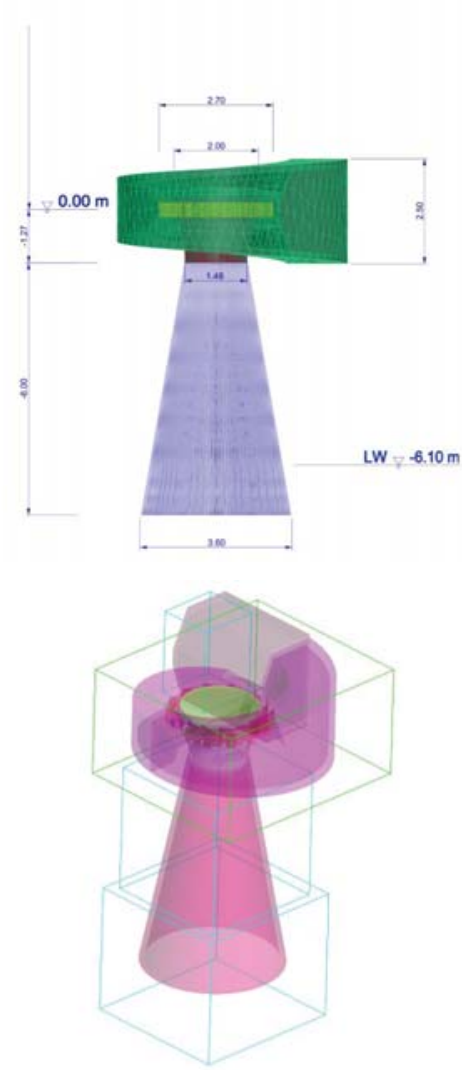

b)
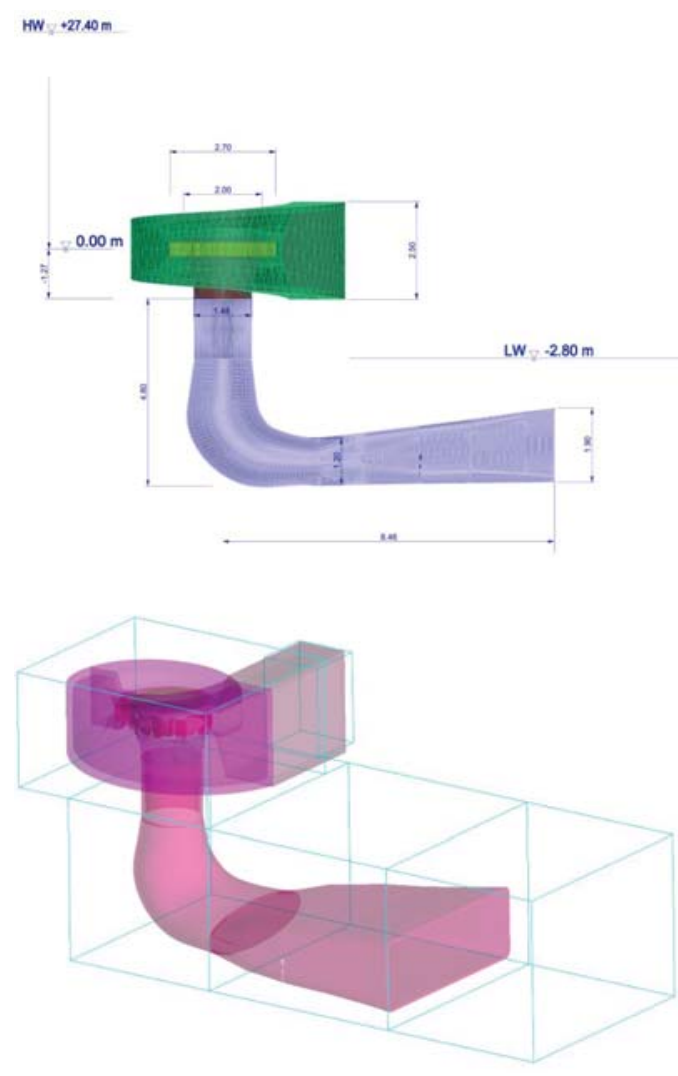

Fig. 2. The part of Alden installation under modelling: a) conical suction pipe, b) pipe bend

\section{Description of the installations under analysis}

The installation to be tested was adapted to the maximum hydraulic head in the Dobczyce power plant [5]. A model turbine diameter equal to $2.0[\mathrm{~m}]$ was assumed. The system feeding water to the turbine rotor was made of a trapezoid cross section spiral and a guide vane with 14 flow channels (Fig. 3-5). 


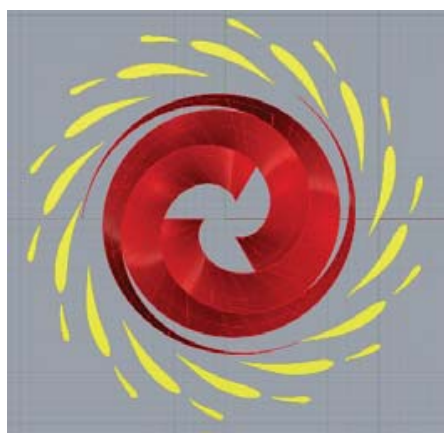

Fig. 3. View of runner of the Alden turbine with guide vane

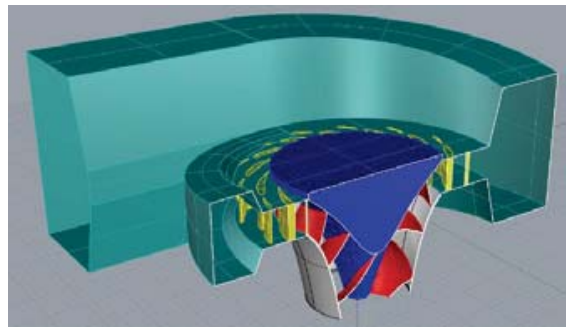

Fig. 4. Crossection of the installation of the Alden turbine

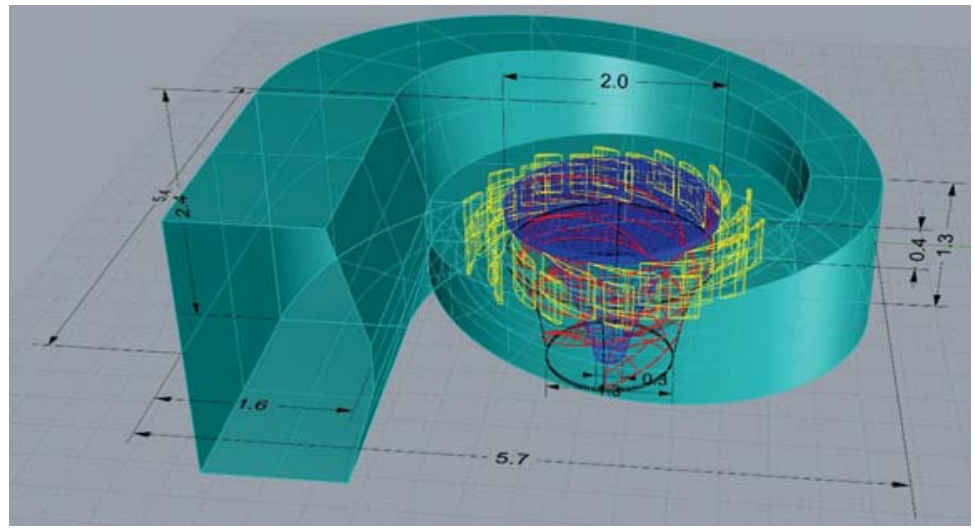

Fig. 5. Dimensions of the Alden turbine system [m]

The calculations were made for the following parameters:

- turbine rotational speed $140\left[\mathrm{~min}^{-1}\right]$,

- upper water surface elevation: +30.00 [m asl]

- lower water surface elevation: -0.20 [m asl], in the case of a pipe bend

- lower water surface elevation -3.50 [m asl], in the case of a conical suction pipe

- guide vane elevation +2.60 [m asl]

- external pressure assumed: $101325[\mathrm{~Pa}]$ (normal pressure),

- water temperature $5\left[{ }^{\circ} \mathrm{C}\right]$,

- water steam pressure $900[\mathrm{~Pa}]$,

- water density $999.9\left[\mathrm{~kg} / \mathrm{m}^{3}\right]$

- water dynamic viscosity $0.001515[\mathrm{~Pa} \mathrm{~s}]$

The analysis of the simulation results for the turbine operation was performed with the professional Flow-3D - FlowSight post-processing software. The area in which a solution was searched for resulted from a diversification of the grid mesh. The inlet spiral was covered with a $0.02[\mathrm{~m}]$ mesh cubic grid. Other elements within the areas were covered with a $0.05[\mathrm{~m}]$ grid. The spinning parts were described by means of the General Moving Objects made available in the Flow-3D interface. All simulations were performed on an HP Z800 Workstation. 


\section{Hydrodynamic cavitation in hydroelectric power installations}

The effect of hydrodynamic cavitation will occur in a fluid under a pressure field subject to variations in time and space. Such variations are related to fluid expansion up to the critical level at which spaces filled with saturated steam as well as with dissolved gases will appear. While being transported in a running stream towards the zone of increased pressure, they are subject to violent compression at which implosions will occur in the areas filled with steam and gases. For a very low water compressibility, pressure values can reach even $150 \mathrm{MPa}$, which means destruction and erosion of materials. While decreasing pressure isothermally to the level of saturation pressure, the fluid will pass into steam, but this effect is not discontinuous within the fluid space; instead, the steam is released as spherical bubbles from all over the volume. It is assumed that the critical pressure causing a phase transformation is almost equal to the pressure of saturated steam of a fluid in the determined conditions. A fluid pressure variation

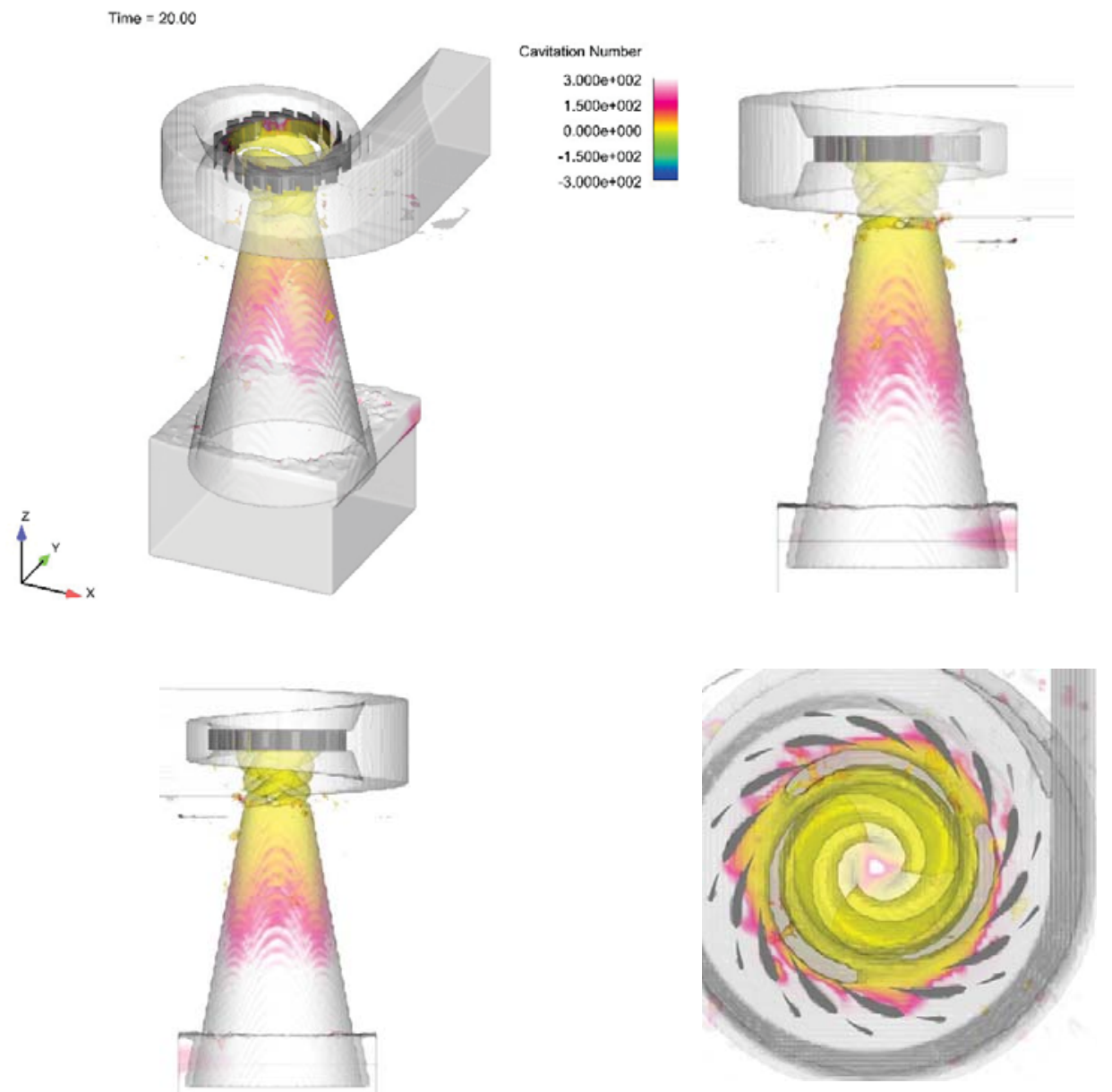

Fig. 6. Cavitation number, conical suction pipe (temperature $5\left[{ }^{\circ} \mathrm{C}\right]$, external pressure: $101325[\mathrm{~Pa}]$, water steam pressure $900[\mathrm{~Pa}])$ 
leads thus to a transformation of the liquid phase into gaseous. The agents influencing the occurrence of cavitation are therefore temperature, pressure and fluid flow rate. Other factors which favour the occurrence of cavitation are also the shape of the surface contacted by the fluid, pollutions in the fluid, and gases dissolved, if any. Cavitation often occurs in the throats of the channels and where flows become curved as well as due to the motion of solids in fluids. It is also caused by a local narrowing of stream lines of the passing fluid or stream detached from the streamlined surfaces of bodies. The effect is influenced by diffusion, degassing, evaporation, condensation, fluid inertia, surface tension, adhesion and fluid viscosity.

While analysing the phenomenon of cavitation, one can determine the parameter or dimensionless number which permits one to perform a quantitative evaluation of flows in two aspects:

- The parameter which assumes an identical value for any and dynamically similar conditions of cavitation;

- The parameter determining the conditions of cavitation-free flow and the conditions for the occurrence, disappearance or development of the respective cavitation phases.

Although in this analysis the effect of cavitation is not modelled, an identification of places where cavitation is likely to occur could be postulated (Fig. 6,7); a reliable indicator is, which describes the propensity for cavitation in the areas concerned:

$$
c_{a}=\frac{\left(p-p_{n}\right)}{\frac{\rho u^{2}}{2}}
$$

where: $c_{a}$ - cavitation number, $p$ - pressure value at a point of flow $[\mathrm{Pa}], p_{n}$ - steam pressure $[\mathrm{Pa}], \rho$ - fluid density $\left[\mathrm{kg} / \mathrm{m}^{3}\right], u$-fluid velocity $[\mathrm{m} / \mathrm{s}]$

Investigations into the effect of cavitation in hydroelectric power installations suggest that both a diminished lower water surface level and a gross increase in the hydraulic head will negatively affect the cavitation conditions in the turbine. As the pressure value in the suction area goes down, pressure fluctuations and vibrations of the turbine shaft will intensify, and therefore, symptoms will appear which may be caused by cavitation and may also contribute to this phenomenon. Such relationships are taken into consideration while designing water power plants; it is checked whether the obtained value of cavitation index exceeds the critical value:

$$
\sigma=H_{B}-\frac{H_{s}}{H}>\sigma_{c}
$$

where $H_{B}$ barometric pressure in $[\mathrm{m}]$ of water column is, $H_{S}$ is suction pressure in $[\mathrm{m}]$ on the turbine outlet or the rotor height above the lower water surface level, $H$ is the hydraulic head of the power plant turbine in $[\mathrm{m}]$. The value of $\sigma_{c}$ may be found by applying appropriate empirical formulae [9]. 

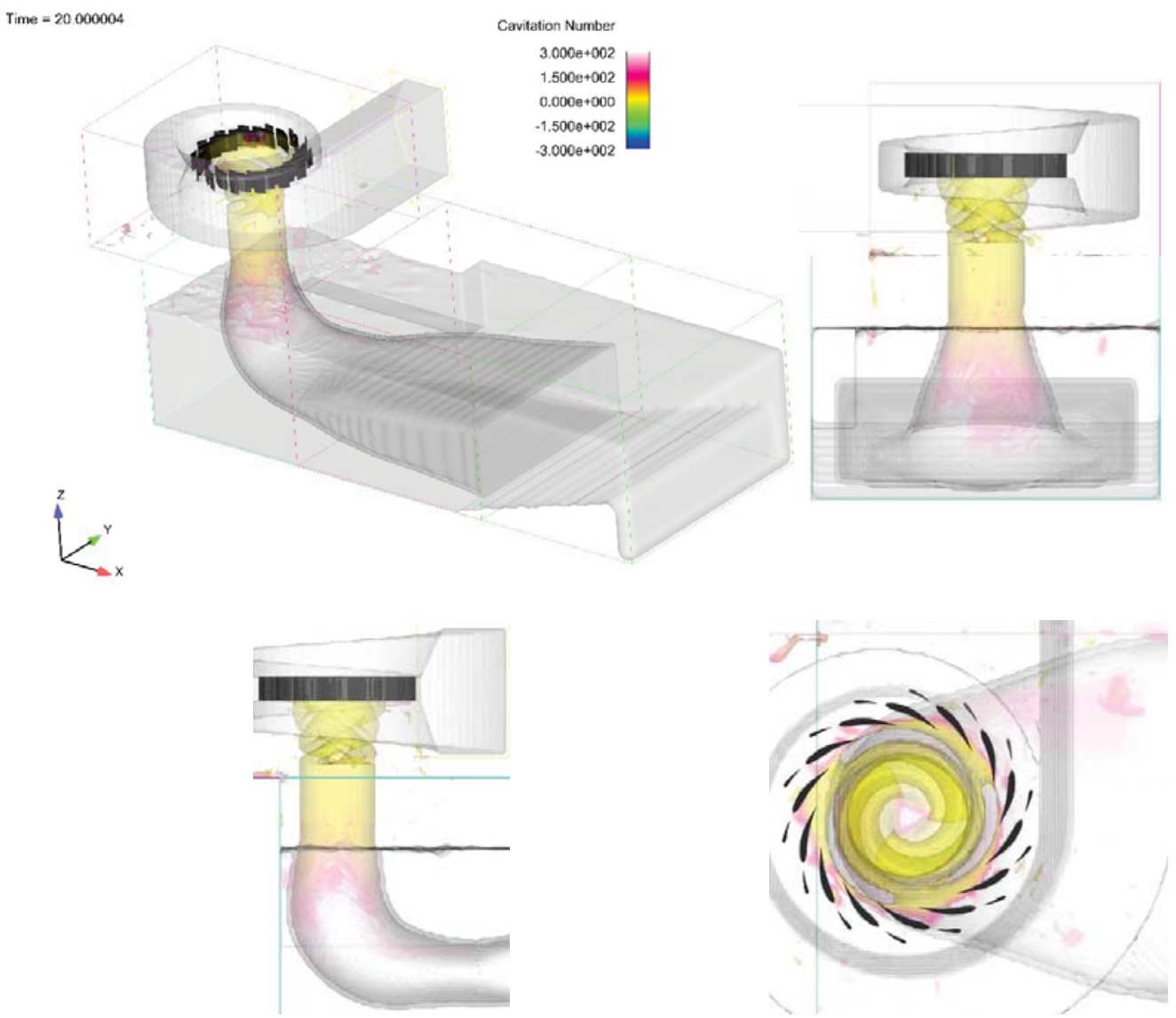

Fig. 7. Cavitation number, pipe bend (temperature $5\left[{ }^{\circ} \mathrm{C}\right]$, external pressure: $101325[\mathrm{~Pa}]$, water steam pressure $900[\mathrm{~Pa}]$ )

\section{Determination of the vortex core}

While describing flows of real fluids, two forms of flow are considered: laminar (ordered) and turbulent (violent, chaotic). The principal criterion for separating these two forms from each other is the Reynolds number. The loss of stability of the laminar flow and its transition into a turbulent flow results from an excessive increase in the inertial forces vs. the forces of internal friction which act upon moving water particles. In the turbulent flow there will appear spatial vortexes of various length scales (small, medium and large), which means the occurrence of small, non-stationary departures of velocity fields and pressure from average values, and eventually, the turbulent flow will become spatial and chaotic. Numerous vortexes which enter into interactions may be curved or twisted, which brings about a rotation in several different planes of each single vortex, which, in turn, will impede the identification and visualization of this effect. 
The scales of turbulent vortexes cover the range from $10^{-6}[\mathrm{~m}]$ (scale of dissipative processes constituting one of the essential features of turbulence) to an order of metres (technical applications) or even hundreds and thousands of miles (geophysical turbulence) continuously [10]. An infinite number of relationships existing among the respective scales of the effect, and in each of them, the processes of turbulent transport of mass, momentum or scalar energy (energy, heat) will cause interactions in the form of an infinite cascade of vortexes performing transport processes in a manner typical of turbulent flow. This means that the intensity of mass, momentum and energy transport is a few orders of magnitude higher than for laminar flow.

Vortexes will occur because of free and forced dissemination in the zone of turbulent flow. The occurrence of a vortex is of consequence for pressure fluctuations, which affects the initiation of the effect of cavitation, since the pressure value at the centre of a vortex may be considerably lower than the average pressure within the flow area. After the discovery of vortex structures in the turbulence, interest was immediately aroused in doing research into the vortex, which resulted in a series of methods used for identifying vortexes. One makes use of several classifications (Yuning Zhang [7]); in general, one may enumerate so-called objective and subjective methods; in the former case, the methodology of vortex identification will not affect its shape. Instead, the objective methods rely mainly upon invariants of vortex structures viz. Galileo, Lagrange or rotations.

One of the objective methods based upon the tensor of velocity gradient for the identification of vortex areas is the Q-criterion.

The velocity gradient tensor $\bar{D}$ may be given as:

$$
D_{i j}=\frac{\partial u_{i}}{\partial x_{j}}
$$

Second rank tensors are subject to well-known mathematical operations typical of the vector space. However, unlike conventional vectors in the Euclidean space, extra operations, like transposition, superposition or inverse may be defined for them. In addition, each second rank tensor may be separated additively into its symmetric and antisymmetric parts.

$$
D_{i j}=S_{i j}+\Omega_{i j}
$$

where:

$$
\begin{array}{r}
S_{i j}=\frac{1}{2}\left(\frac{\partial u_{i}}{\partial x_{j}}+\frac{\partial u_{j}}{\partial x_{i}}\right) \\
\Omega_{i j}=\frac{1}{2}\left(\frac{\partial u_{i}}{\partial x_{j}}+\frac{\partial u_{j}}{\partial x_{i}}\right)
\end{array}
$$

where:

$S_{i j}$ - symmetric tensor

$\Omega_{i j}$ - tensor called tensor. 
The characteristic equation for may be given as follows:

$$
\lambda^{3}+P \lambda^{2}+Q \lambda+R=0
$$

$P, Q$ i $R$ are three invariants of the velocity gradient tensor. With a separation into the symmetric and antisymmetric tensor parts, the invariants may be expressed as follows

$$
\begin{gathered}
P=-\operatorname{tr}(\bar{D}) \\
Q=\frac{1}{2}\left(\operatorname{tr}(\bar{D})^{2}-\operatorname{tr}\left(\bar{D}^{2}\right)\right)=\frac{1}{2}\|\bar{\Omega}\|^{2}-\|\bar{S}\|^{2} \\
R=-\operatorname{det}(\bar{D})
\end{gathered}
$$

In this analysis, the motion vorticity was assessed using the Q- criterion (Hunt, Wray\& Moin, 1988, [11]), which corresponds to the second invariant of the velocity gradient tensor. The criterion complies with the identification of big scale vortexes in a turbulent flow of incompressible fluids. It identifies the areas of flows in which the forces generating the rotation exceed the forces of internal frictions (Fig. 8, 11).

This criterion identifies the vorticity as an area with a positive second invariant of tensor $\nabla u, Q>0$.

In this criterion a second condition for pressure, which should be lower than the pressure value in the vortex neighbourhood, is also added. Looking at the definition, the second invariant expresses the local equilibrium between the strain rate at shearing and the vortex size. Its positive value indicates that the vorticity value is higher than the strain rate.

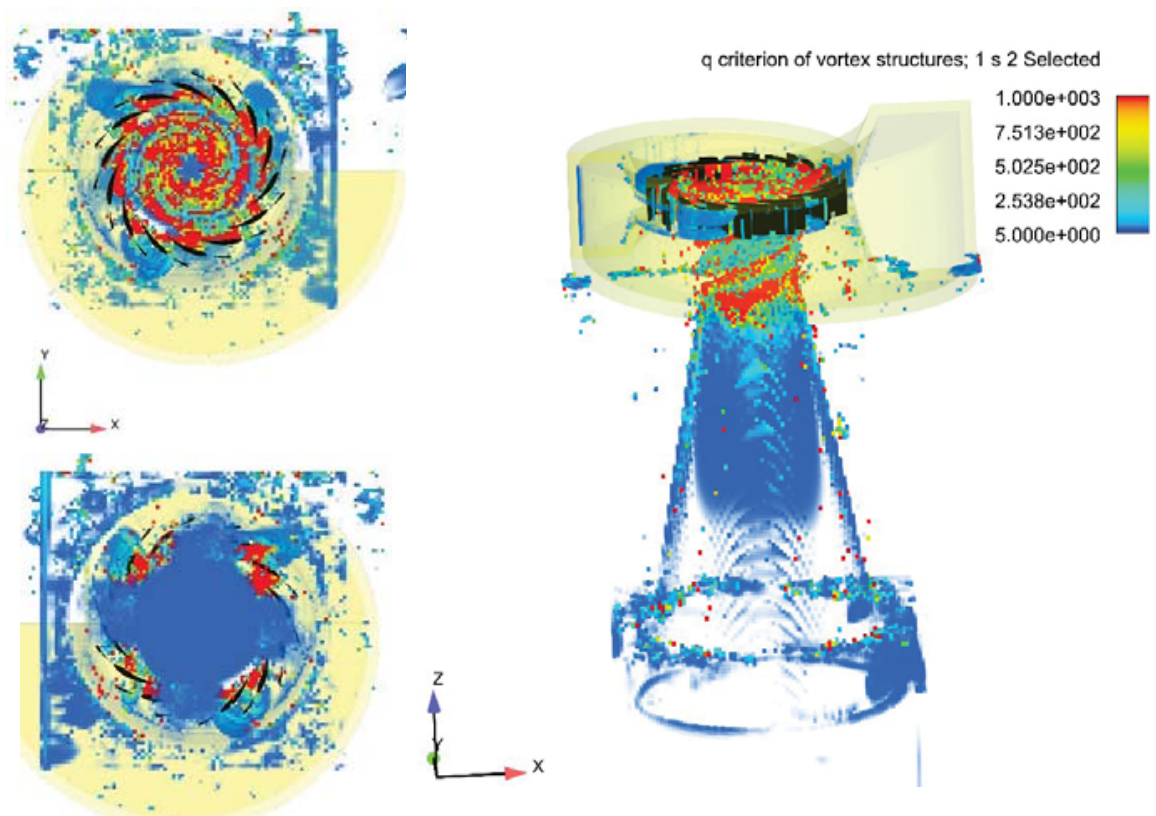

Fig. 8. Vorticity in the Alden installation with a conical pipe according to the Q-criterion 

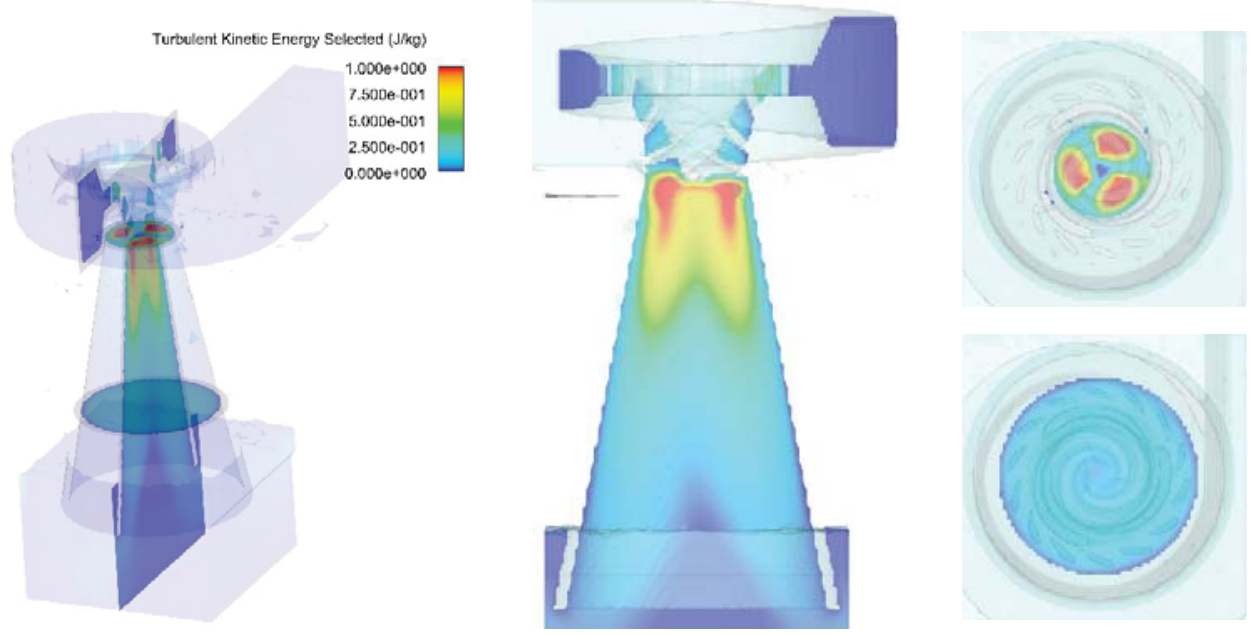

Fig. 9. Turbulent kinetic energy in the Alden installation with a conical pipe
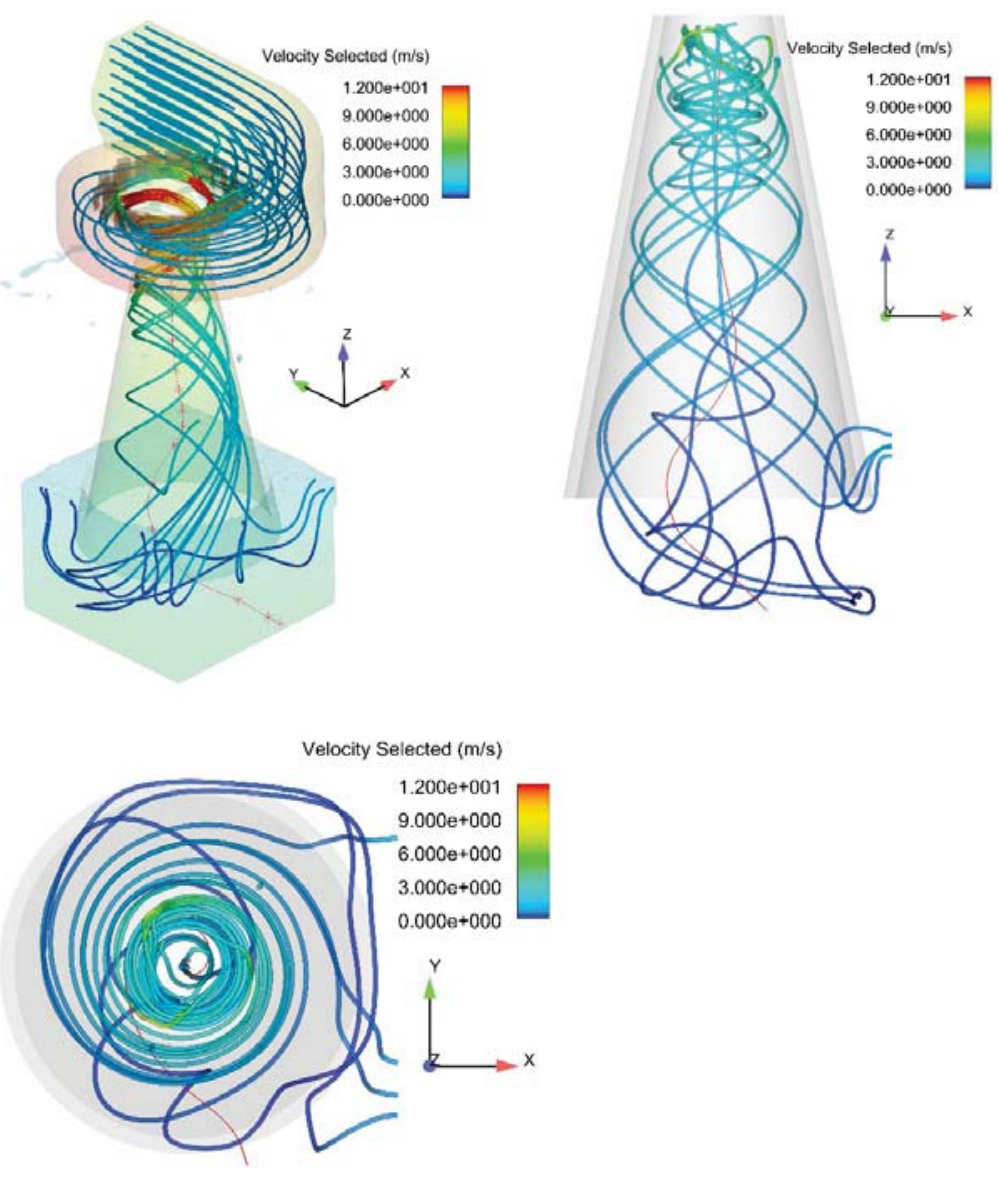

Fig. 10. Vortex core in the conical suction pipe against the stream line 


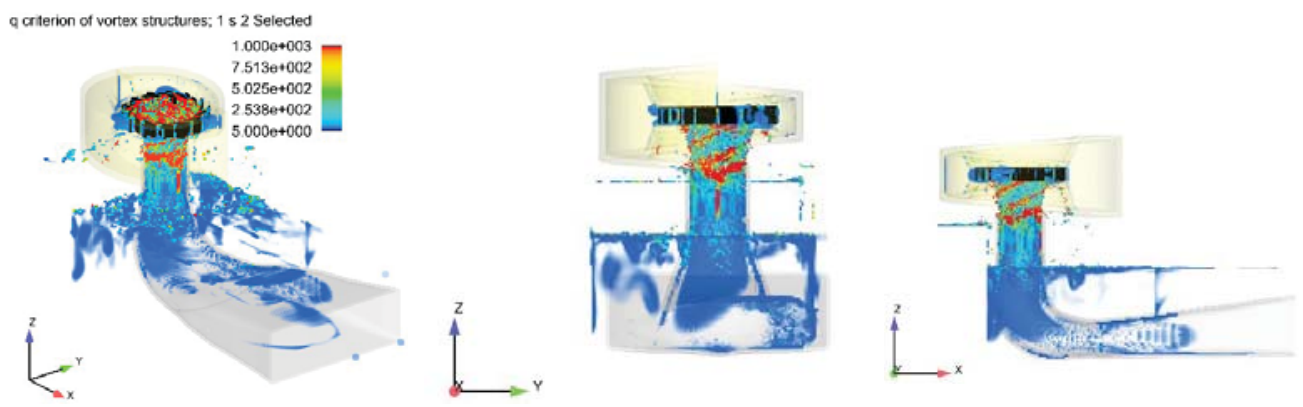

Fig. 11. Vorticity in the Alden installation with a pipe bend according to the Q-criterion
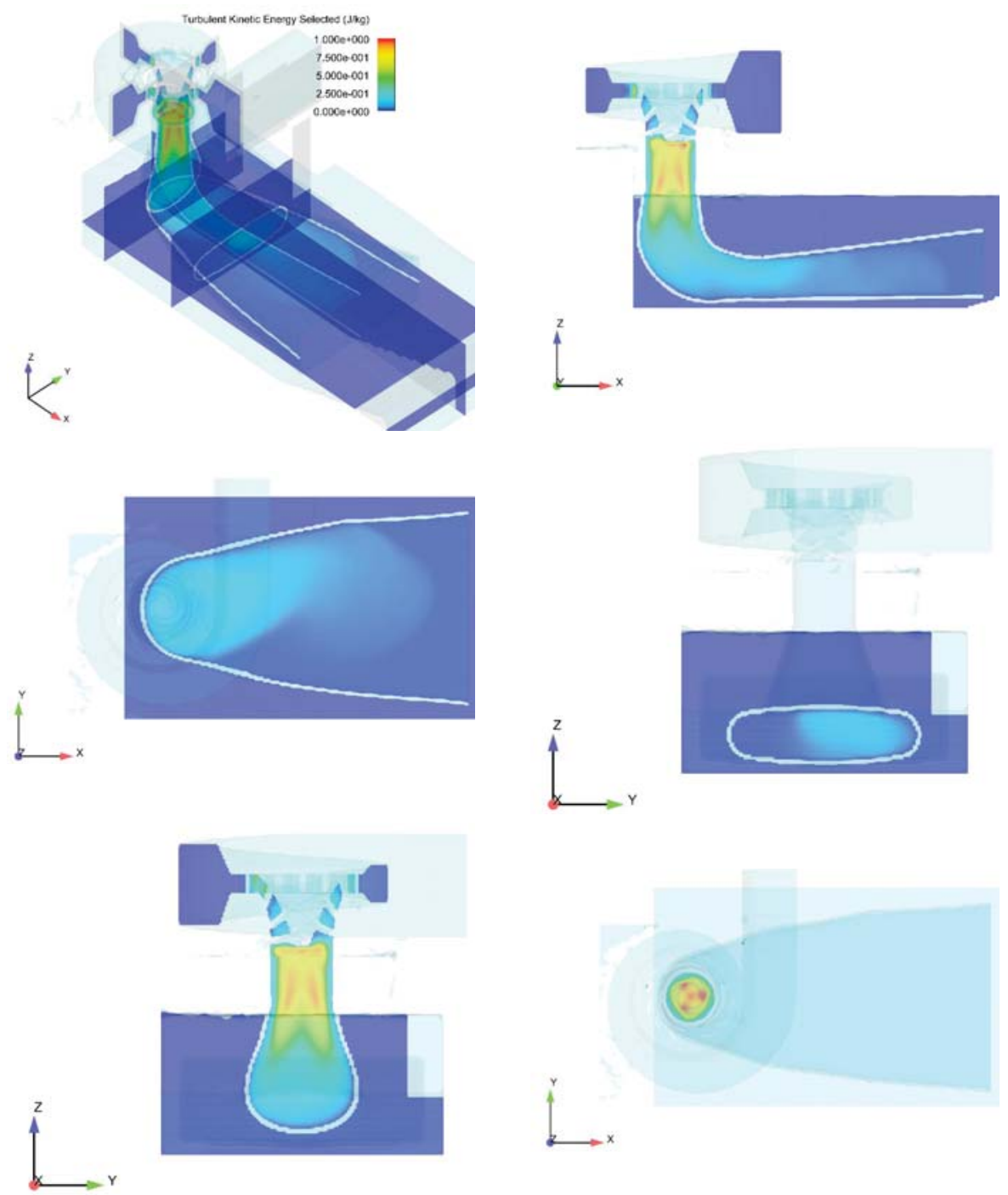

Fig. 12. Turbulent kinetic energy in the Alden installation with a pipe bend 

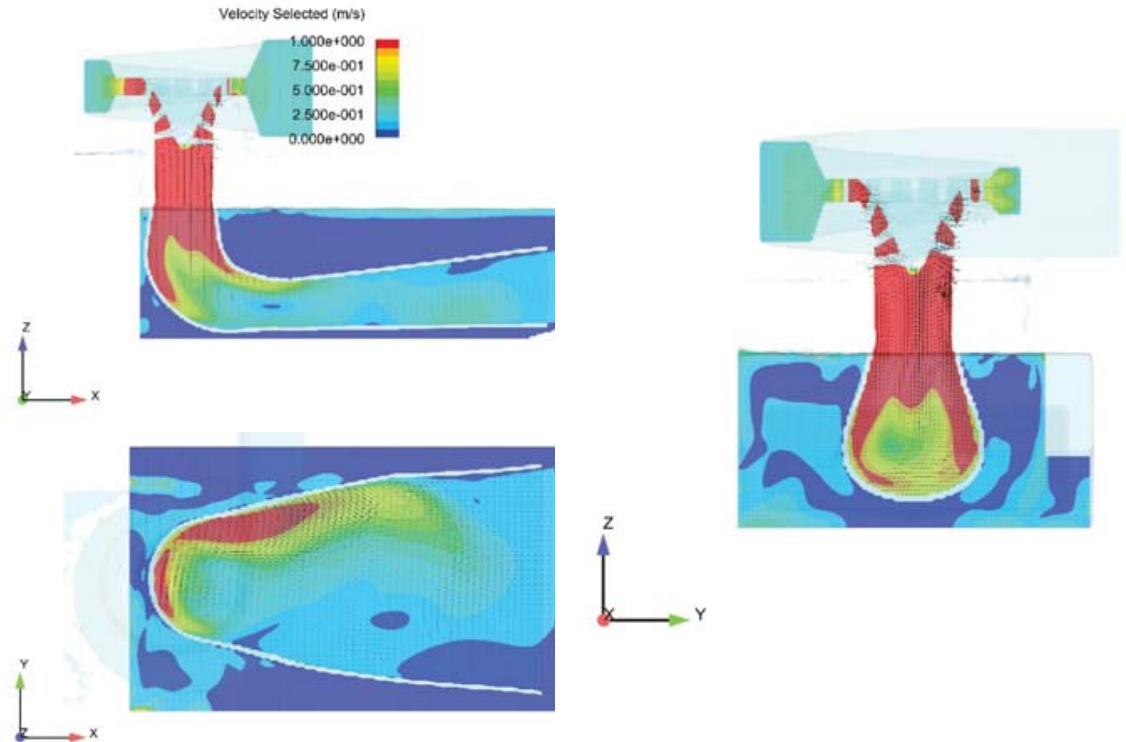

Fig. 13. Vectors of velocity field in selected cross sections the Alden installation with a pipe bend (under $1[\mathrm{~m} / \mathrm{s}]$ )
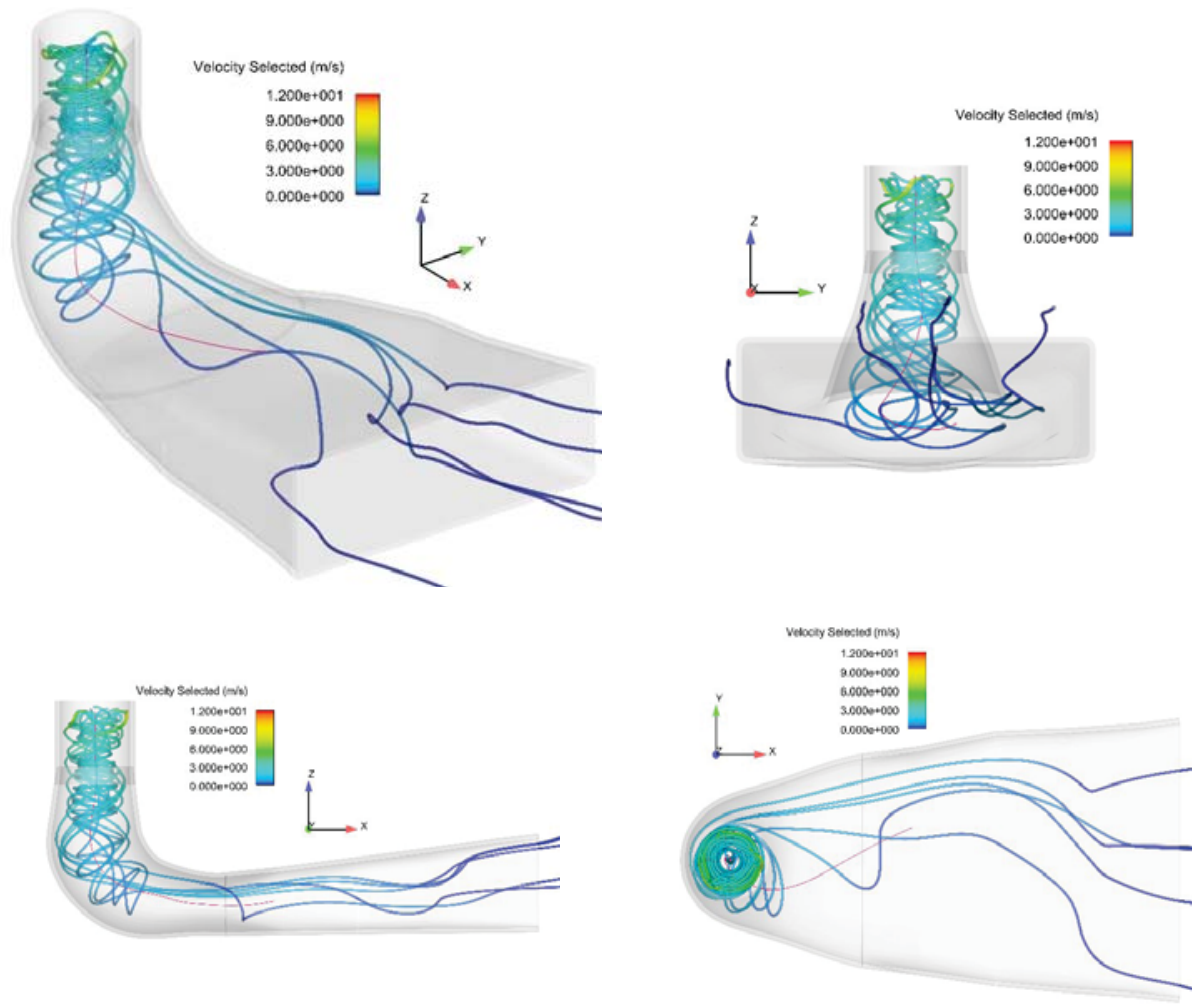

Fig. 14. Vortex core in a pipe bend against the stream line 
The vortex core line was set out with an algorithm for determining eigenvalues (Robert Haimes and David Kenwright [6]). In short, the applied algorithm divides the search area into elementary subareas. For each of them a unique form of the velocity gradient tensor is determined. While using the algorithm for the analysis of eigenvalues the reduced velocity values at nodal points are determined which, in turn, allow one to identify the areas of elementary subareas pierced by the vortex core. The set of those lines enables the determination of the shape and course of the vortex core (Fig. 10, 14).

\section{Hydrodynamic loads in the suction pipe}

The water flow through the turbine set is characterized by large pressure fluctuations. The amplitude of oscillations increases towards the rotor and then decreases towards the suction pipe outlet. Statistical curves of fluctuations are variable and depend on the location of the analysis point (Tab. 1,2). Figures 18 and 21 show the course of fluctuation in time for the pressure obtained for the model at the points situated:

- under the rotor at the suction pipe jacket (Point no. 1) (Fig. 15, 18),

- under the turbine rotor in its axis (Point no. 2) (Fig. 15, 18),

- in the rotor axis immediately above the lower water surface (Point no. 3) (Fig. 15, 18),

- in the turbine inlet behind the guide vanes (Point no. 4) (Fig. 15, 18).

Table 1. A list of statistics of pressure fluctuations for selected points; suction conical pipe

\begin{tabular}{|c|c|c|c|c|c|}
\hline Statistics & Unit & Point no. 1 & Point no. 2 & Point no. 3 & Point no. 4 \\
\hline Mean & {$[\mathrm{Pa}]$} & 57154.67 & 51479.60 & 100095.50 & 381890.75 \\
\hline $\begin{array}{c}\text { Standard } \\
\text { deviation }\end{array}$ & {$[\mathrm{Pa}]$} & 18847.41 & 12787.10 & 5224.37 & 64915.96 \\
\hline $\begin{array}{c}\text { Coefficient of } \\
\text { variation }\end{array}$ & {[]} & 0.33 & 0.25 & 0.05 & 0.17 \\
\hline
\end{tabular}

Table 2. A list of statistics of pressure fluctuations for selected points; suction pipe in the form of a bend

\begin{tabular}{|c|c|c|c|c|c|}
\hline Statistics & Unit & Point no. 1 & Point no. 2 & Point no. 3 & Point no. 4 \\
\hline Mean & {$[\mathrm{Pa}]$} & 91853.87 & 80086.01 & 97274.15 & 374043.40 \\
\hline $\begin{array}{c}\text { Standard } \\
\text { deviation }\end{array}$ & {$[\mathrm{Pa}]$} & 28563.55 & 23675.69 & 20665.33 & 42839.28 \\
\hline $\begin{array}{c}\text { Coefficient of } \\
\text { variation }\end{array}$ & {[]} & 0.31 & 0.30 & 0.21 & 0.11 \\
\hline
\end{tabular}

The rotor structure, revolutions per minute and the number of guide apparatus channels indicate that the highest level of harmonic components will appear at frequencies of approx. 2.33, 7.00, 32.67, $98.00[\mathrm{~Hz}]$. The spectral analysis performed confirms the dominating frequencies of pressure fluctuations (Fig. 17, 20). Those frequencies are strictly related to the rotor rotational speed, the number of flow channels and the number of rotor vanes. In the 
case under analysis, we have 3 rotor blades, 14 guide apparatus flow channels mating with the rotor moving at a rotational speed of $140\left[\mathrm{~min}^{-1}\right]$. The main source of oscillations will be flow fluctuations caused by the rotor and guide apparatus vanes. Actually, the values of those fluctuations are also influenced by cavitation effects at the fluid discharge from the rotor.

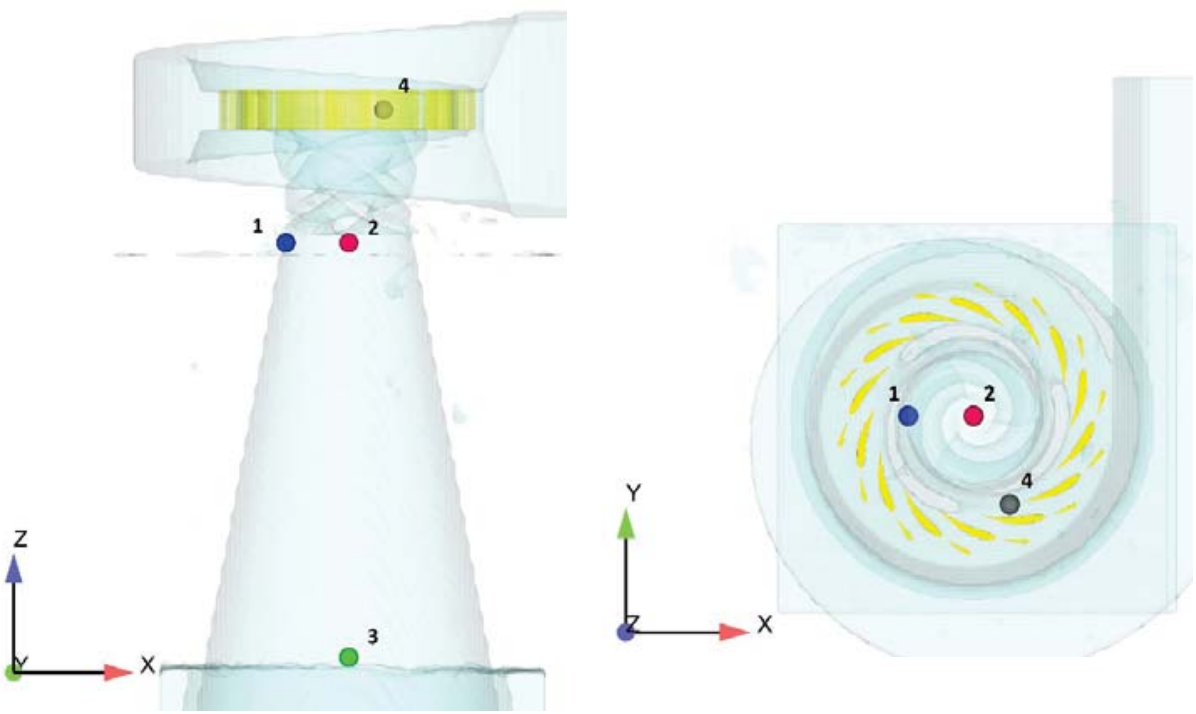

Fig. 15. Arrangement of measurement points - conical pipe

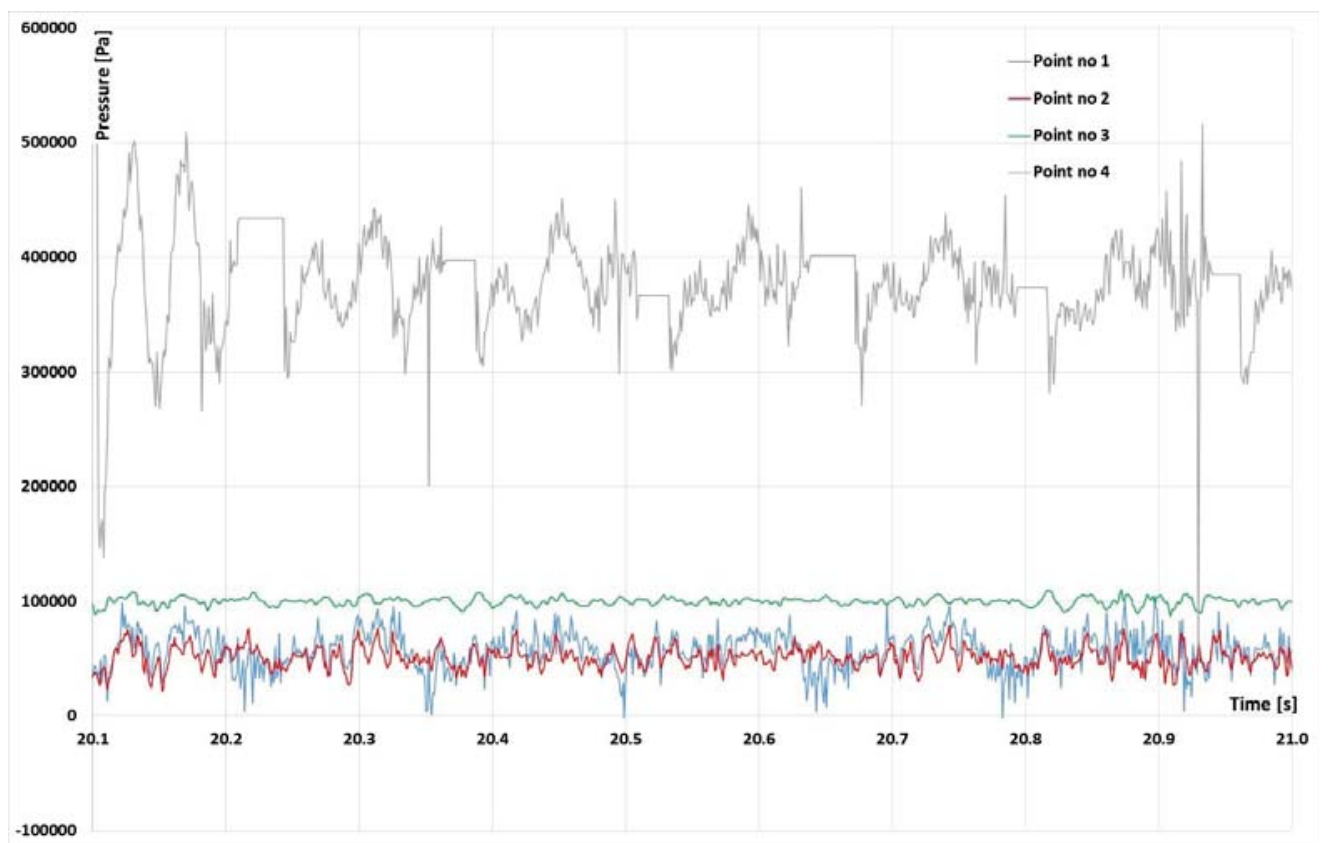

Fig. 16. Pressure fluctuations in the installation with a conical suction pipe 


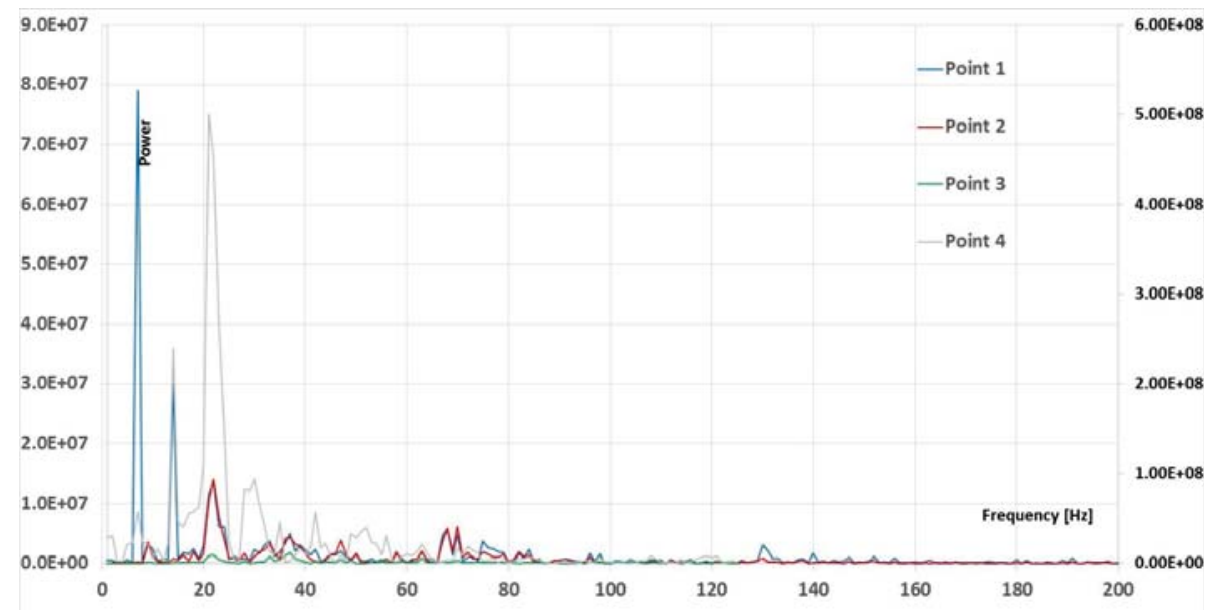

Fig. 17. Spectral analysis of pressure fluctuations in the installation with a conical suction pipe

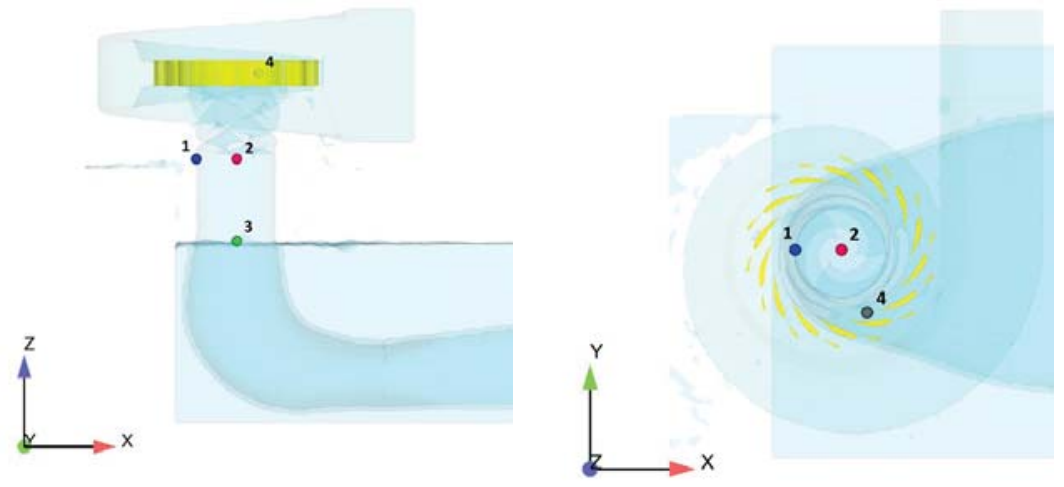

Fig. 18. Arrangement of measurement points - pipe bend

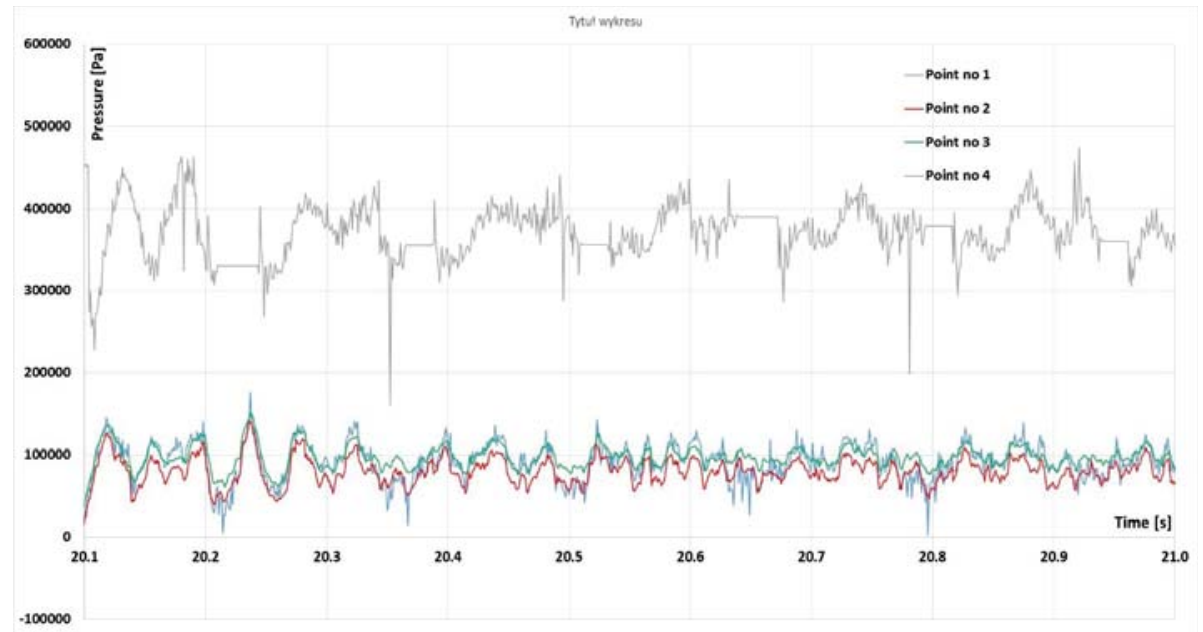

Fig. 19. Pressure fluctuations in the installation with a pipe bend 


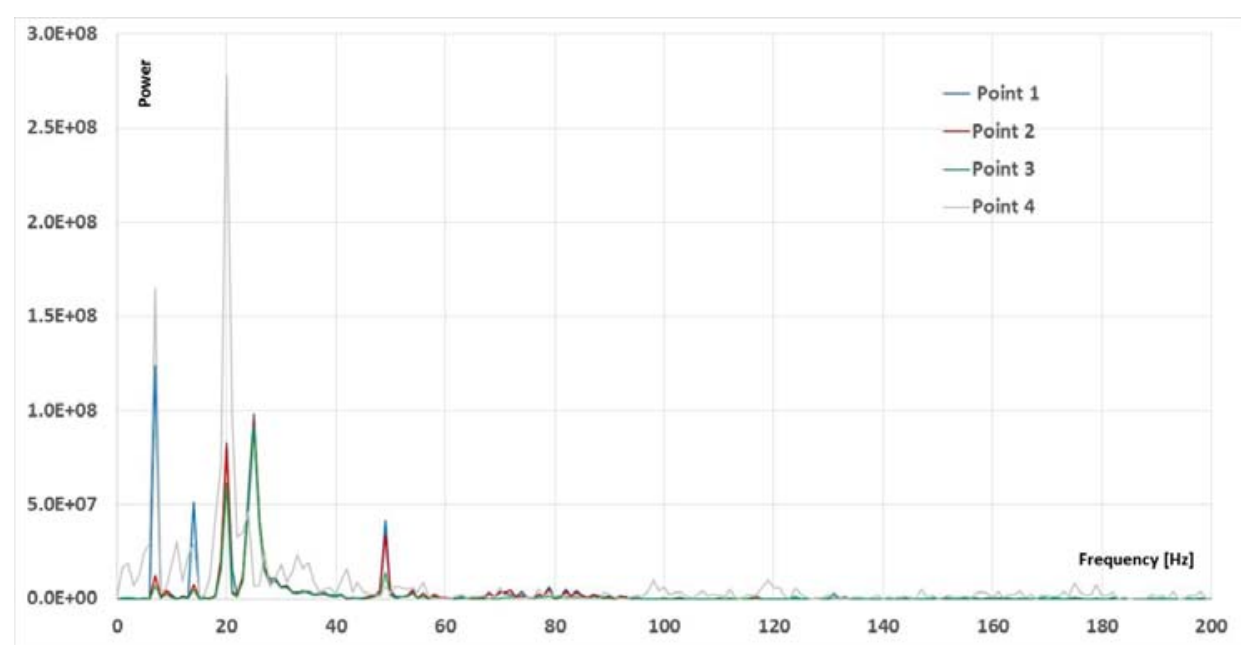

Fig. 20. Spectral analysis of pressure fluctuations in the installation with a pipe bend

\section{Stresses and strains in selected parts of the hydroelectric power installations}

In order to determine stresses and displacements of selected parts of the installation, the FSI model was selected. The suction pipes and the inlet spiral of the installation were analysed. For each part a stress distribution is presented according to the effort theory of von Mises.

The criterion for the maximum reduced stress by von Mises is based upon the theory of von Mises-Hencky, also referred to as Distortion-Energy Theory or the Maximum Distortion Energy Criterion. According to the theory, yielding of a ductile material begins when the reduced stress according to Mises becomes equal to the limiting stress. In most cases, the limiting stress is used as the yield point; however, Flow-3D software allows the user to use a subjective limiting stress (Fig. 21-23).

$$
\sigma_{V M}=\sqrt{\frac{3}{2} \sigma_{i j} \sigma_{i j}-\frac{1}{2}\left(\sigma_{k k}\right)^{2}}
$$

where:

$\sigma_{i j}$ - elements of Cauchy stress tensor

The discrete grids in the area have been arranged in such a way that constraints for the elements under investigation are guaranteed. A simulation model has been defined for a linear operating range of those elements - within the area described by Hooke's law [12].

D'Alambert's principle is the basic equation describing the solid body motion, used to solve FSI problems [12]

$$
\rho \frac{d^{2} x}{d t^{2}}=\nabla \boldsymbol{\sigma}+\rho \mathbf{b}
$$


where:

$\rho$ - solid body density,

$t$ - time,

$x$ - coordinates of the points

$\boldsymbol{\sigma}$ - Cauchy stress tensor

$\mathbf{b}$ - mass forces

In the approach slight, gradual deformations calculated from the formula were applied:

$$
E^{\prime}=\frac{1}{2}\left\{[\nabla(\delta x)]^{T}+\nabla(\delta x)\right\}=\frac{1}{2}\left[\frac{\partial(\partial x)_{i}}{\partial x_{j}^{n}}+\frac{\partial(\partial x)_{j}}{\partial x_{j}^{n}}\right] e_{i} e_{j}
$$

where:

$E^{\prime}$ - increase in strain

$i, j \quad$ - indices to describe the Cartesian coordinates in directions

$e_{i} \quad$ - unit vector in the system

$\delta x$ - describes the displacement vector

$$
\delta x=x^{n+1}-x^{n}
$$

where:

$x^{n} \quad$ - is the position of the preceding point in the solid body at moment $n$

$x^{n+1}$ - is the position of the point in the solid body $j$ at moment $n+1$

The Cauchy stress tensor for the moment $n+1, \sigma^{n+1}$ is obtained from the linear Hooke's model:

$$
\sigma^{n+1}=\sigma^{n}+\left(K-\frac{2}{3} G\right) \operatorname{tr}\left(E^{\prime}\right)+2 G E^{\prime}
$$

where:

$n, n+1$ - are time indices

K - volumetric modulus of elasticity

G - modulus of non-dilatational strain,

$\operatorname{tr}\left(E^{\prime}\right)$ is a trace of the strain tensor, viz. a sum of its elements on the main diagonal.

In the algorithm, relationships between material constants are used:

$$
K=\frac{E}{3(1-2 v)}, \quad G=\frac{E}{2(1+v)}
$$

The conditions of the acceleration (127) are solved according to the location of the points at various times:

$$
\rho \frac{d^{2} x}{d t^{2}}=\rho\left(\frac{x^{n+1}-2 x^{n}+x^{n-1}}{\Delta t^{n+1} \Delta t^{n}}\right)
$$



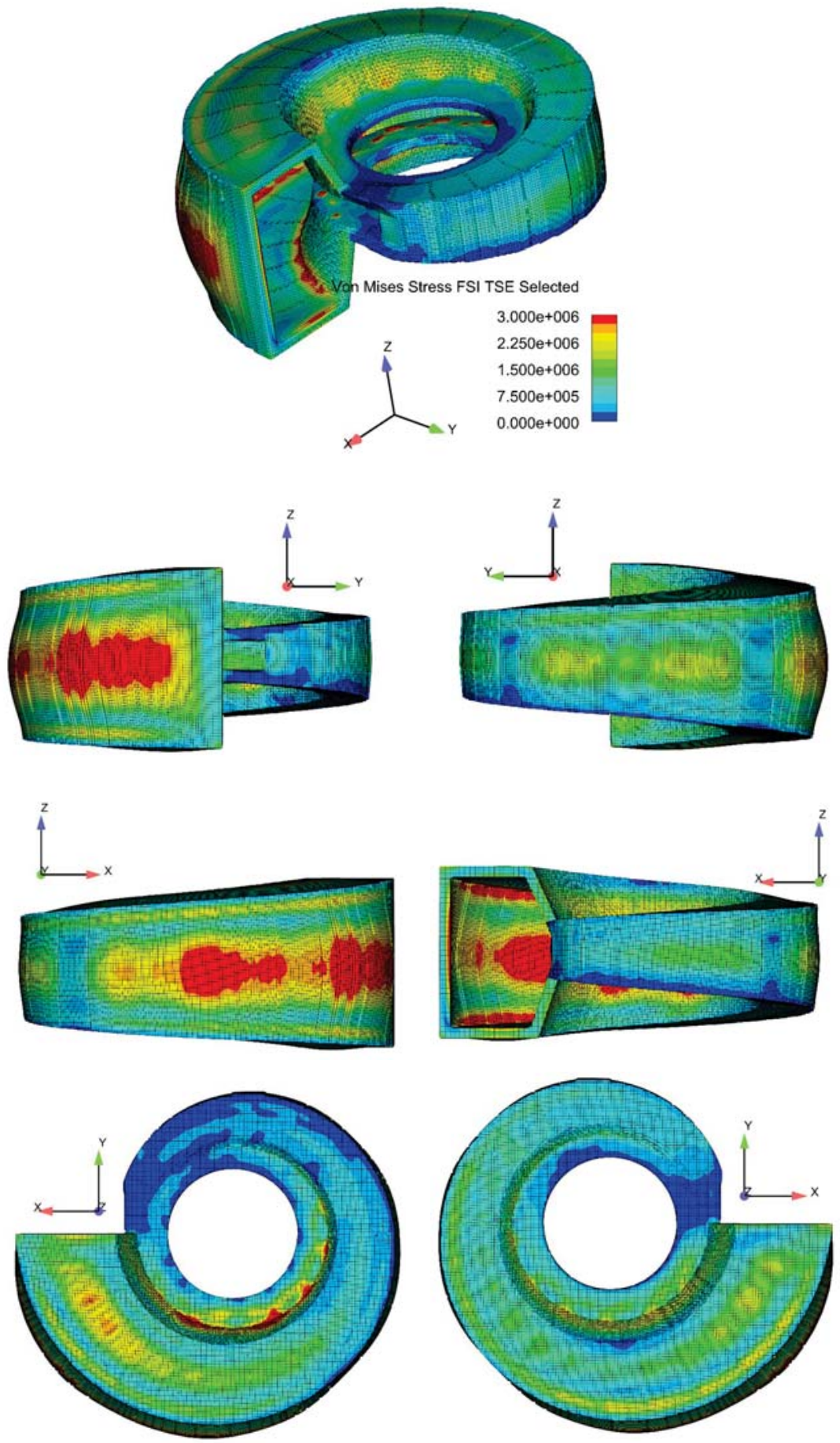

Fig. 21. Stresses according to Mises theory $[\mathrm{Pa}]$ against deformed elements in non-uniform scale - inlet spiral 

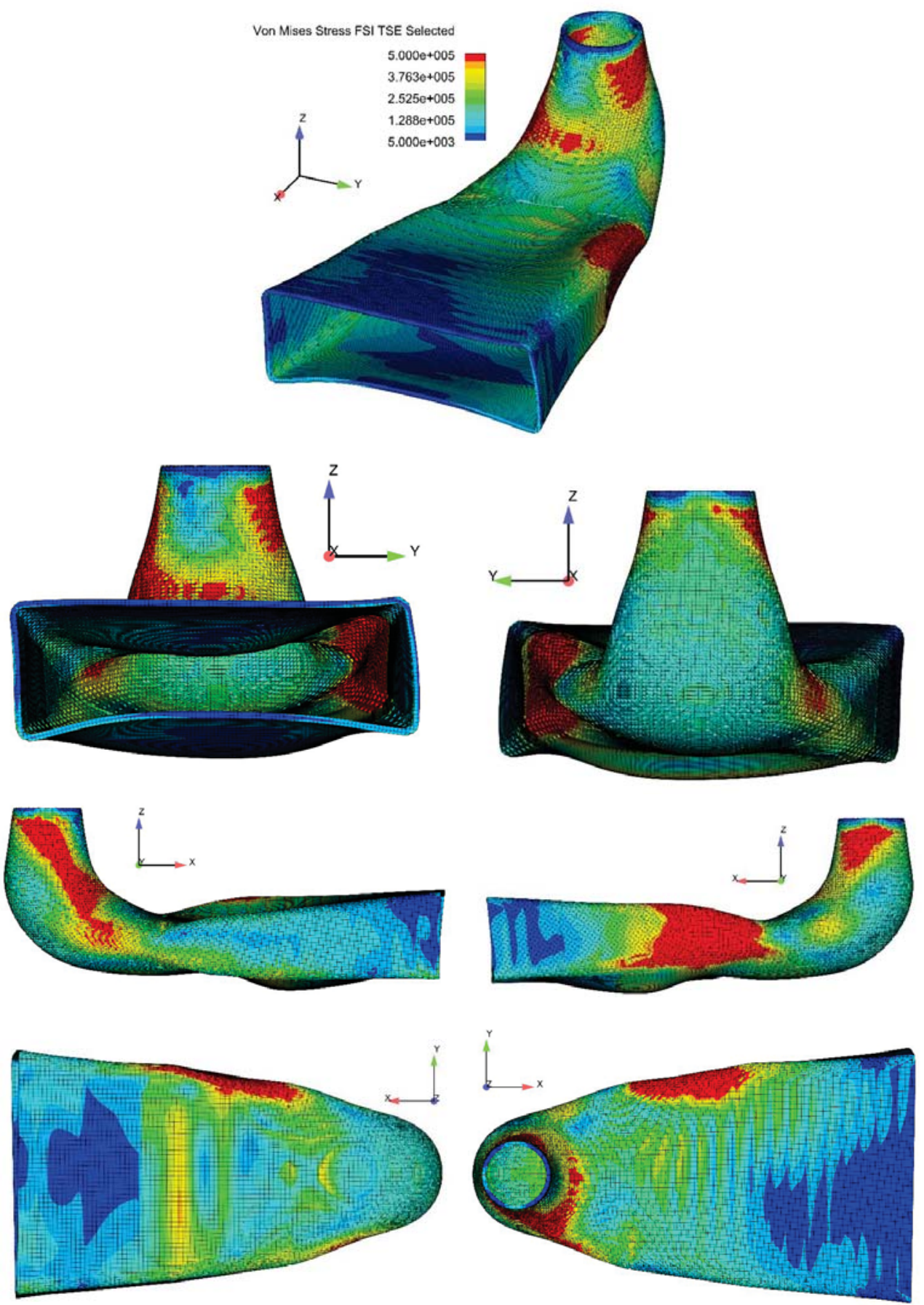

Fig. 22. Stresses according to Mises theory $[\mathrm{Pa}]$ against deformed elements in non-uniform scale, pipe bend 

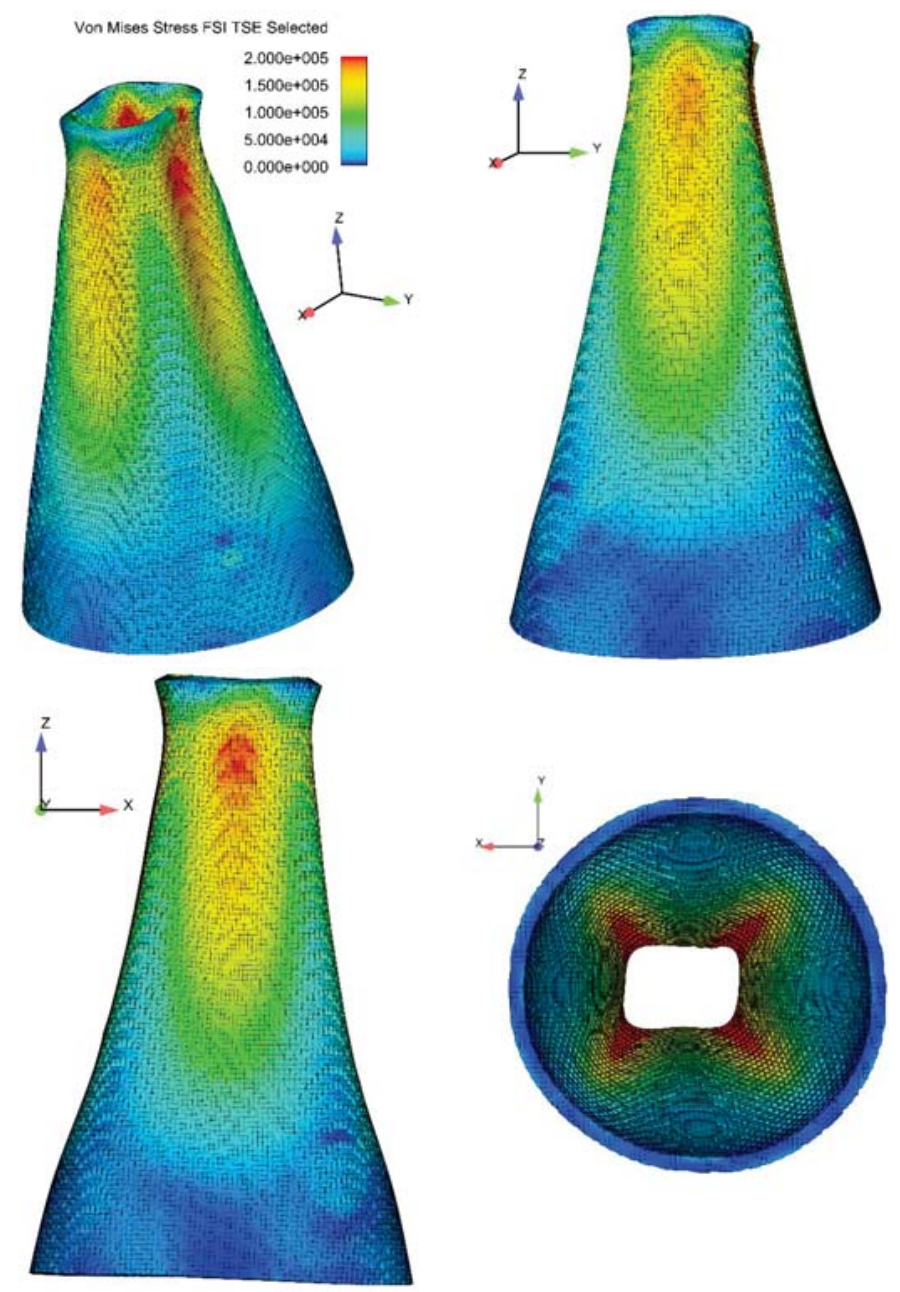

Fig. 23. Stresses according to Mises theory [Pa] against deformed elements in non-uniform scale, conical suction pipe

The interaction of the fluid and the solid area as well as the evolution of the stress tensor will determine the boundary conditions on the solid surface. If the solid surface contacts the fluid, then the local pressure determines the force of interaction $\boldsymbol{n} \sigma^{n+1}$. Therefore:

$$
\boldsymbol{n} \sigma^{n+1}=-n p_{\text {fluid }}
$$

For all parts of hydroelectric power installation subject to FSI analysis the following parameters of materials were assumed:

- material - steel

- density $7700\left[\mathrm{~kg} / \mathrm{m}^{3}\right]$

- Young's modulus $2.15 \mathrm{e}+11[\mathrm{~Pa}]$

- Poisson's rate 0.3 


\section{Ecological criteria for the operation of the installations under analysis}

The consideration of the environmental criteria and standards aimed at minimizing the negative environmental impact of turbines is becoming one of the fundamental principles applied in the choice of hydroelectric power installations. Most serious harm is done to the fish population. The variability of pressure, velocity, strains and sudden changes of shapes and geometry of the channels in which a fish can move will decrease its survival rate.

The trajectory to be covered by a fish moving from the upper to the lower station contains a series of factors affecting its strength. Zones occur with sudden pressure increases and decreases, cavitation areas where a fish is exposed to abrasion, hitting, crushing and turbulences. The Alden turbine is one among few where at the design stage it was tried to regard the environmental criteria established by [2]. The criteria are shown below:

- peripheral velocities of the rotor should not exceed $12[\mathrm{~m} / \mathrm{s}]$,

- the minimum pressure in the rotor should not be under $69[\mathrm{kPa}]$,

- the rate of pressure variation in the rotor should be under $550[\mathrm{kPa} / \mathrm{s}]$,

- the rate of velocity variation in the shearing zone should not exceed $4.5[\mathrm{~m} / \mathrm{s}]$ per $2.54[\mathrm{~mm}]$,

- the rate of shearing stress variations should be not higher than $180[\mathrm{~m} / \mathrm{s} / \mathrm{m}]$,

- the spacing between the rotary and stationary parts should be shorter than $2[\mathrm{~mm}]$,

- the flow channel in the rotor should be as large as possible,

- the number and length of rotor blade edges should be minimized.

At the location points at the guide apparatus inlet provided as a mobile measuring point moving as water flowed by. The measured values of pressure and velocity are shown below

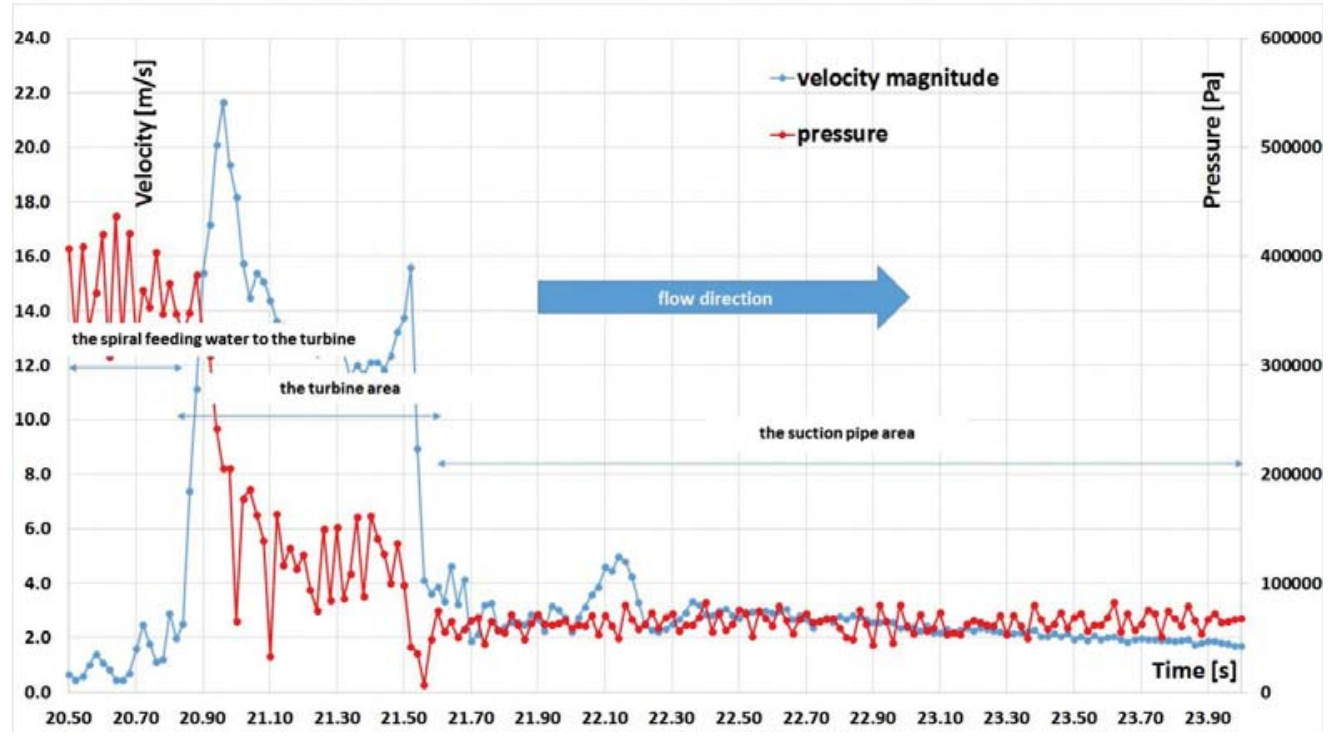

Fig. 24. Record of pressure and velocity values at the mobile measuring point 
(Figure 24). In the figure, three areas are marked: the area of the spiral feeding water to the turbine, the turbine area and the suction pipe area. Each of those areas was described with the pressure and velocity values recorded at the mobile measuring point moving as water flows by.

\section{Summary}

The results presented in conjunction with the analyses have been entirely obtained from CFD modelling. Not all analyses are directly feasible in the proposed post-processing interfaces of Flow-3D or FlowSight. Some analyses required resorting to advanced FlowSight techniques through enquiries, definition of variables or by using programming.

Attention was focused not only on the development of models, simulations and analyses of results, but attempts were also made at contemporary analytical methods for solving CFD problems. The application of the Navier-Stokes equation also referred to as the Reynolds equation was described in brief. For the specific nature of the problem under investigation, a modification resulting from the necessity of regarding the turbulent momentum flux in the Reynolds tensor was described. The most onerous problems occurring in the operation of hydroelectric power installations are described: cavitation, vorticity and hydrodynamic loads. Some results for mechanical and biomechanical analyses are presented. For the selected parts of the system - viz. the inlet spiral and the suction pipe - their stress distributions according to the effort theory of von Mises are displayed, as well as a picture of the parts deformed.

\section{References}

[1] Alto P., "Fish Friendly" Hydropower Turbine Development and Deployment: Alden Turbine Preliminary Engineering and Model Testing [M], Washington D.C.: 2011.1019890, USA, E Electric Power Research Institute, 3420 Hillview Avenue, Palo Alto, California 94304$1338,2011$.

[2] Cook T.C., Hecker G.E., Amaral S.V., Stacy P.S., Lin F., Taft E.P., Final report-pilotscale tests Alden/Concepts NREC Turbine [M], Holden MA, USA, Prepared for U.S. Department of Energy, Washington, DC., USA, Contract No. DE-AC07-99ID13733, 2003.

[3] Fay C., Hecker G., Hogan T., Perkins N., Alden Turbine Market Analysis for New York State, Final Report, Report Number 13-19 [M], Albany, New York, New York State Energy Research and Development Authority, Alden Research Laboratory, Inc., 2012.

[4] Orszag S.A., Yakhot V., Flannery W. S., Boysan F., Choudhury D., Maruzewski J., Patel B., Renormalization Group Modeling and Turbulence Simulations [C], International Conference on Near-Wall Turbulent Flows, Tempe, Arizona, 1993.

[5] Twaróg B., An analysis of the application of the Alden turbine - a case study of the Dobczyce hydroelectric power plant [J], Technical Transactions, 1-Ś/2015, 147-156. 
[6] Haimes R., Kenwright D., On the velocity gradient tensor and fluid feature extraction [C], 14th Computational Fluid Dynamics Conference, Fluid Dynamics and Co-located Conferences, Norfolk,VA,U.S.A., https://doi.org/10.2514/6.1999-3288, 1999, (access).

[7] Zhang Y., Liu K., Xian H., Du X., A review of methods for vortex identification in hydroturbines [J], Renewable and Sustainable Energy Reviews, 81, 2018, 1269-1285.

[8] Kumar P., Saini R.P., Study of cavitation in hydro turbines-A review [J], Renewable and Sustainable Energy Reviews 14, 2010, 374-383.

[9] Bogusławski A., Drobniak S., Tyliszczak A., Turbulencja - od losowości do determinizmu, Modelowanie Inżynierskie [M], Gliwice, Instytut Maszyn Cieplnych, Politechnika Częstochowska, 2008, 41-48.

[10] Haller G., An objective definition of a vortex [J], Journal of Fluid Mechanics, 525, 2005, $1-26$.

[11] Hou G., Wang J., Layton A., Numerical Methods for Fluid-Structure Interaction A Review [J], Communications in Computational Physics, 12, 2, 2012, 337-377. 